This item was submitted to Loughborough's Research Repository by the author.

Items in Figshare are protected by copyright, with all rights reserved, unless otherwise indicated.

\title{
"Oh" + apology + solution: a practice for managing the concomitant presence of a possible offense and a problem-to-be-solved
}

PLEASE CITE THE PUBLISHED VERSION

http://dx.doi.org/10.1080/0163853X.2015.1056692

\section{PUBLISHER}

Routledge (๑) Taylor \& Francis)

VERSION

AM (Accepted Manuscript)

\section{PUBLISHER STATEMENT}

This work is made available according to the conditions of the Creative Commons Attribution-NonCommercialNoDerivatives 4.0 International (CC BY-NC-ND 4.0) licence. Full details of this licence are available at: https://creativecommons.org/licenses/by-nc-nd/4.0/

\section{LICENCE}

CC BY-NC-ND 4.0

\section{REPOSITORY RECORD}

Pino, Marco, Loredana Pozzuoli, Ilaria Riccioni, and Valentine Castellarin. 2019. "“oh” + Apology + Solution: A Practice for Managing the Concomitant Presence of a Possible Offense and a Problem-to-be-solved". figshare. https://hdl.handle.net/2134/19002. 
"Oh" + Apology + Solution: A Practice for Managing the Concomitant Presence of a Possible Offense and a Problem-to-be-solved

Marco Pino ${ }^{1}$, Loredana Pozzuoli, Ilaria Riccioni and Valentine Castellarin

Published as Pino, M., Pozzuoli, L., Riccioni, I., \& Castellarin, V. (2016). “Oh” + Apology +

Solution: A Practice for Managing the Concomitant Presence of a Possible Offense and a Problemto-be-solved. Discourse Processes, 53(1-2), 47-62.

\footnotetext{
${ }^{1}$ Loughborough University. Email: M.Pino@lboro.ac.uk
} 
Pino, Pozzuoli, Riccioni and Castellarin - "Oh” + Apology + Solution

\begin{abstract}
:
In this paper we examine a turn construction $(\mathrm{Oh}+$ Apology + Solution $)$, which speakers employ to deal with the concomitant presence of a possible offense and a problem-to-be-solved in the immediately preceding interactional environment. We show that speakers collaborate in differentiating the offense-aspect and the problem-aspect of an emerging circumstance by treating the apology-component as preliminary to and in the service of the primary function of the turn: treating the circumstance as a problem-to-be-solved and providing a solution for it. The "Oh" prefacing, which treats the circumstance as something of which the speaker had not been previously aware, and the turn-medial positioning of the apology contribute to treating the matter at hand as a minor shortcoming or imposition rather than a major wrongdoing.
\end{abstract}


Pino, Pozzuoli, Riccioni and Castellarin - "Oh" + Apology + Solution

\section{Introduction}

Social interaction is permeated by the possibility that aspects of anyone's conduct may turn out to have, more or less inadvertently, offended others by violating norms about socially appropriate and morally acceptable behaviour (Robinson, 2006; Schegloff, 2005). In principle, several aspects of social conduct can be vulnerable to later being treated as having generated possible offenses, whose level of seriousness can vary from minor impositions or shortcomings to aggravated wrongdoings. Another element of variation is how more or less significant breaches of social and moral norms are brought up in conversation. Sometimes a possible offense is first pointed at by its producer (e.g. through a pre-emptive apology; Robinson, 2004; 2006), whereas in other cases the first mention is done by the recipient of the offense. In the following instance reported by Schegloff (2005) a callrecipient, Norm, mentions that he was already in bed when Bonnie called. This report comes across as a complaint and Bonnie produces an apology in next turn. By "Oh" prefacing the apology, Bonnie displays that she has just become aware of a circumstance that has transformed an otherwise innocent behaviour into a possible offense.

(1) (Schegloff, 2005, p. 456)

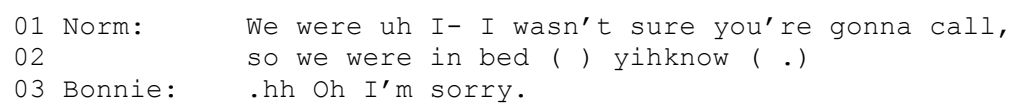

By apologising, the recipient of a complaint acknowledges the existence of an offense, takes responsibility for it, appreciates how it might have caused the recipient some trouble, and works to restore or maintain relational harmony (Robinson, 2004).

Relevant to the focus of this paper is another phenomenon: cases where a party reports a problem, followed by another party's proffering a solution. In the following instance from Schegloff (2007), Betsy mentions a "staffing problem" (lines 3-4) and Alice volunteers a solution in the form of an offer to help. 
(2) (Schegloff, 2007, p. 84)

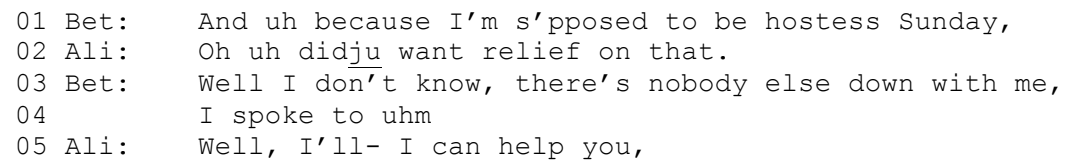

The two sequence types exemplified in extracts 1 and 2 (complaint-apology and problem-solution) can be differentiated in terms of their retrospective and prospective orientations. In the complaintapology sequence, there is a retrospective focus on a past event, its inauspicious consequences for the complainant, and the attendant responsibility of the complaint-recipient/apologiser. In the problemsolution sequence, there is a prospective orientation to a speaker's problem-to-be-fixed and to the recipient's ability to fix it.

This paper is concerned with cases where recipients treat a prior turn as carrying both a retrospective orientation to a possible offense and a prospective orientation to a problem-to-be-solved. We argue that the ["Oh" + Apology + Solution] format is specifically designed to deal with this interactional contingency. We begin by outlining our approach to the dataset; we then illustrate how the ["Oh" + Apology + Solution] turn construction is sequentially deployed to deal with both a possible offense and a concomitant problem-to-be-solved that have just come to speaker's attention. Subsequently we show how speakers and recipients collaborate in differentiating the apologycomponent and the solution-component in terms of their temporal and sequential priorities. Finally, we argue that through this practice speakers propose that a circumstance was a minor imposition or shortcoming (rather than being an aggravated wrongdoing).

\section{Analytic approach}

In our initial approach to the Apologies Data Set we noticed a number of responsive turns where speakers produce a turn-medial apology preceded by a turn-initial "Oh" and followed by a third turn- 
Pino, Pozzuoli, Riccioni and Castellarin - "Oh" + Apology + Solution

component. Having observed that the apology-component does not receive a response, we formulated the hypothesis that the primary function of the turn is not apologising, but instead is responding to an aspect of the prior turn other than its complaint-implicative aspect. After assembling a collection of this phenomenon (6 cases) we noticed that the third turn component is occupied by delivering a solution to a problem that emerged in a prior turn. In this study, we employ a broad notion of "problem", conceived as an impediment that bears on a participant and that can be resolved through another participant's action step.

\section{“Oh" + Apology + Solution}

In this section we examine how each component of the [“Oh” + Apology + Solution] turn construction accomplishes specific interactional work: (1) displaying a change in the speaker's state of awareness in relation to a circumstance that has become available in the prior turn, (2) treating it as a possible offense (conceived as a state of affairs that has negatively affected a recipient, and for which the speaker now takes responsibility) and (3) treating it as a problem which the speaker has the ability to solve. These functions are implemented by three turn components, respectively (1) "Oh", (2) apologetic "sorry" or "I'm sorry", and (3) a solution-to-the-problem. In all cases, the nature of the offense/problem is local or internal to the interaction (Heritage and Raymond, this volume). In the following extracts, the single arrow indicates the point where a possible offense/problem emerges and the double arrow indicates the ["Oh" + Apology + Solution] turn.

\section{(3) [NB:I:3:1-2]}

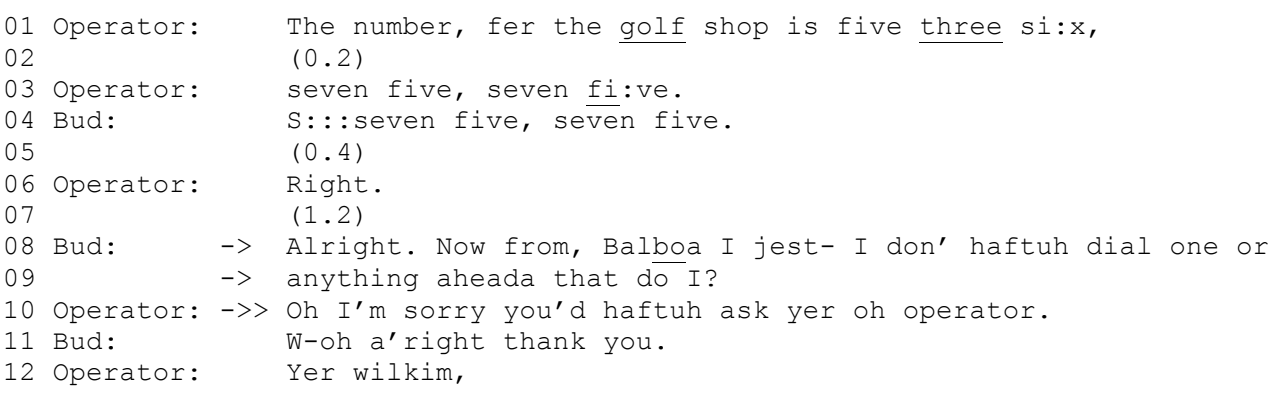


Pino, Pozzuoli, Riccioni and Castellarin - "Oh" + Apology + Solution

Bud has called directory enquiries to inquire about the telephone number of a golf course in Hunnington Beach. After provision of the number by the operator (lines 1-3), Bud's partial repeat (line 4) and the operator's confirmation (line 6), the interaction reaches a point where possible completion of the sequence is made contingent upon the caller's acceptance of the information (for a similar pattern, see Kevoe-Feldman \& Robinson, 2012). A gap emerges (line 7), possibly signalling a problem with the information provided (Kendrick \& Torreira, 2015). Acceptance is produced at line 8 ("Alright"), creating a point where speakers could start closing the call. Nevertheless, Bud expands his turn to ask whether the number should be preceded by an area code (lines 8-9). Being formatted as a request for information (rather than, for example, as a complaint for not having received the information he needed), Bud's turn appears designed to present a problem-to-be-solved. At the same time, it has the potential to expose a possible 'offense' (specifically a shortcoming on the operator's part): it appears that the operator has been working on the assumption that Bud is calling from the local area, whereas he is calling from a location (Balboa) that is not covered by the telephone area code of the place where the golf course is taking place (see lines 2-3). The information the operator has provided at lines 1 and 3 is thus insufficient. The target turn at line 16 ("Oh" + Apology + Solution) addresses this emerging issue. The turn initial "Oh" indexes a shift in the operator's awareness (Heritage, 1984; 1998), displaying a here-and-now realisation that she had been working under a false assumption. She goes on to treat this misapprehension as a possible offense through the apologetic "I'm sorry". She then produces a solution turn component by which she treats the circumstance as a problem-to-be-solved: Bud will have to call an operator in his local area. Through the turn construction at line 10 , then, the operator treats the prior turn as presenting both a possible offense and a problem-to-be-solved. The apology component displays a retrospective orientation to a speaker's misapprehension as originating a shortcoming (the delivery of incomplete information and a consequent delay in the resolution of Bud's request) whereas the solution component has a prospective orientation to what the speaker can to resolve the recipient's problem (having properly aligned her knowledge regarding Bud's circumstances, the operator delivers information that 
Pino, Pozzuoli, Riccioni and Castellarin - "Oh" + Apology + Solution

technically completes the request sequence although it turns out that she cannot provide the information Bud was looking for).

(4) $[$ Holt:2:7:1-2]

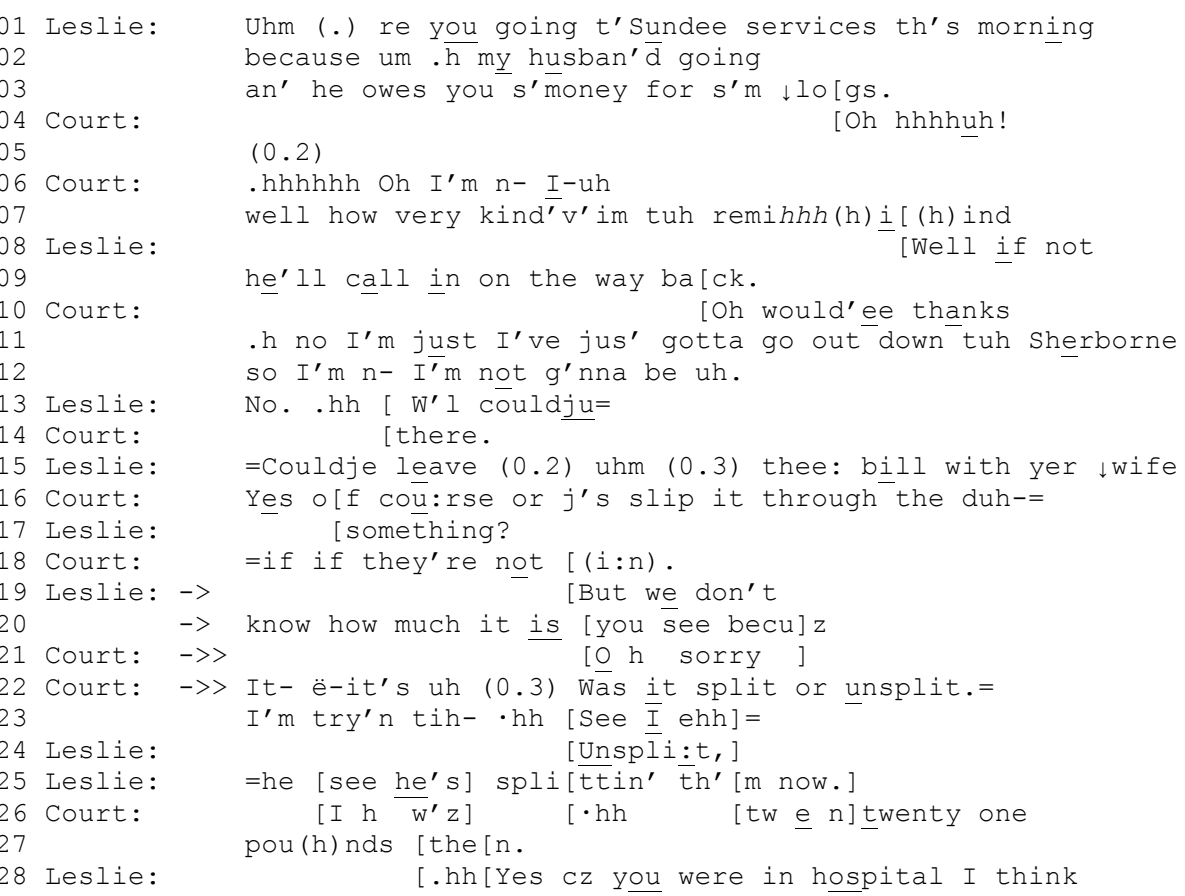

Leslie has called to arrange the payment of some logs that Court had previously made available to her husband (lines 6-7). After making two unsuccessful proposals from line 1 to line 9, Leslie proposes that Court leave the bill with his wife (lines 13-15), hence possibly making it available that she and her husband do not know the amount of money. When Court suggests that, if no-one is home then Leslie's husband could slip the money through the door (lines 16, 18), Leslie objects that her husband cannot implement the proposed line of action because they do not know the amount of money (lines 19-20). Leslie formulates a problem-to-be-solved in the form of a lack of relevant knowledge for the business at hand ("But we don't know how much it is you see"). Her turn has also the potential to expose a possible offense (specifically a shortcoming) on Court's part: not only has Court assumed that Leslie already knew the amount of money, but he has also put her in the position where she has to do an overt request about money (which she may have tried to avoid at lines 13-15). Court employs the ["Oh" + Apology + Solution] turn construction to deal with this. Through the turn-initial "Oh" 
Pino, Pozzuoli, Riccioni and Castellarin - "Oh" + Apology + Solution

Court treats the circumstance as something about which he had not been previously aware. Through the apologetic "sorry" he goes on to treat this newly realised information as a possible offense on his part. Finally, by expanding his turn with a post-apology solution component, he displays an orientation to the matter raised by Leslie as a problem-to-be-solved (she needs to know the amount of money to comply with the proposed plan). In this case, the solution to the problem is delayed by the production of an insert-expansion at lines 22-25 (Schegloff, 2007) to establish the conditions for the delivery of the solution; after being informed that the logs were "unsplit" (lines 24-25), Court communicates the price of the logs (lines 26-27).

(5) [Holt:SO88:1:2:1-2]

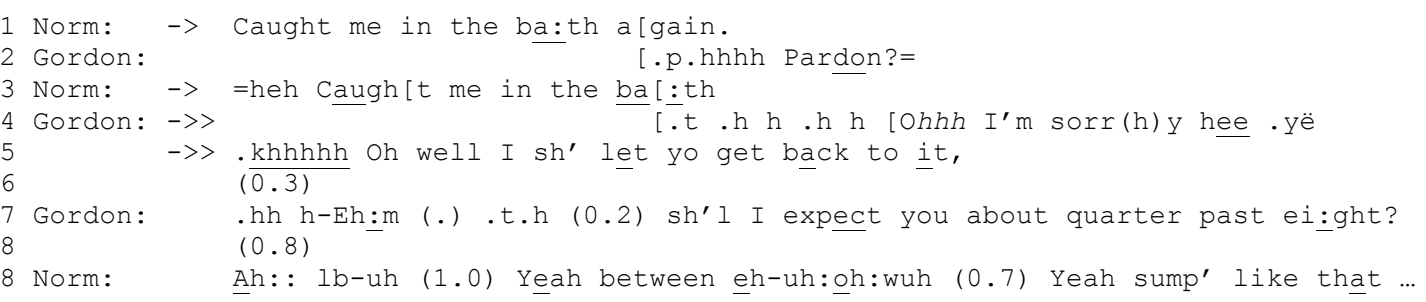

Gordon has called to ask Norm for a lift to an event that they are both attending. Relevant to the type of offense/problem emerging in this call is that the ringing tone had gone twelve times before Norm answered the phone. After granting the request and following Gordon's expression of gratitude (data not shown), Norm produces the turn in line 1, which can be heard as a complaint ("Caught me in the ba:th again") but can also make available a problem that the caller can alleviate (by providing for a quick termination of the call). After Norm's partial repeat of the complaint at line 3 ("again" is dropped), Gordon employs the construction [“Oh" + Apology + Solution] at lines 4 and 5. The turn initial "Ohhh" registers the matter evidenced in the prior turn as something of which the speaker had not been previously aware. Gordon then treats the matter as a possible offense for which he takes responsibility through the apologetic "I'm sorr(h)y" (the number of rings before Norm answered the phone could have alerted Gordon to the bad timing of his call and offered him an opportunity to produce a pre-emptive apology; see Schegloff, 1986; see also extract 8, line 14). After some laughter 
Pino, Pozzuoli, Riccioni and Castellarin - "Oh” + Apology + Solution

particles, Gordon produces a solution turn component with which he offers to terminate the call ("Oh well I sh' let yo get back to itt"). Through the [“Oh” + Apology + Solution] construction Gordon displays both a retrospective orientation to a possible offense and a prospective orientation to a problem-to-be-solved.

(6) [Holt:2:2:2:1]

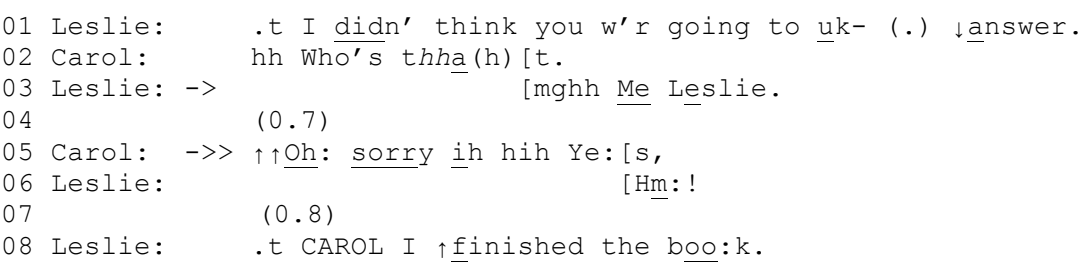

We lack access to the opening of this call. Nevertheless, it appears that Leslie has relied on voicerecognition to provide for caller identification (Schegloff, 1986), which the call recipient (Carol) has failed to achieve. In line 2, Carol explicitly asks the caller to self-identify, which Leslie does in line 3. In accordance with the preference for caller recognition in telephone interaction (Schegloff, 2007, pp. 88-89), Leslie makes Carol accountable for having failed to recognise her, first by indexing familiarity through the reference term "me", then by producing her own first name without the surname. Through this format she thus points to a possible 'offense'. After a gap in line 4, Carol

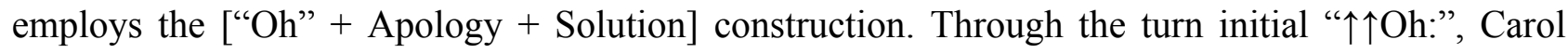
registers that something new emerged in the prior turn, i.e. both Leslie's identity and her own failure to recognise her, and she treats the latter as a shortcoming for which she takes responsibility through “sorry" (hence matching Leslie's conveyed assumption that recognition should have taken place; see Emmersten \& Heinemann, 2010). Carol then produces a post-apology turn expansion to solve the problem that emerged in the prior turn (failed recognition and consequent delay in the progressivity of the call): after two laughter particles Carol produces a "Ye:s" token which confirms recognition and forwards the call. Through the ["Oh" + Apology + Solution] turn construction, Carol displays both a retrospective orientation to the failed recognition as her own shortcoming and a prospective orientation to the failed recognition as a problem-to-be-solved. 


\section{(7) [Deutsch:CDII:88-89]}

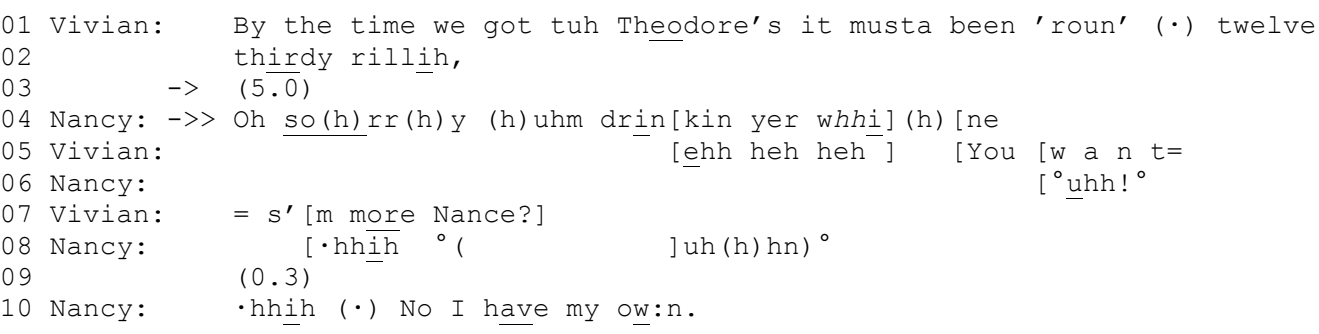

Two couples are having dinner together. In the silence at line 3, Nancy reaches for and drinks from a glass. Michael turns toward her and follows her movement with his gaze. This appears to alert Nancy to the fact that she has used Michael's glass, a possible offense which she articulates at line 4 after having already started putting down the glass. Unlike extracts $3-6$, here it is the speaker who articulates the nature of an offense/problem which has become available through means other than verbal production. This can account for the more expanded ["Oh" + "sorry" + naming of the offense/problem] format (Heritage and Raymond, this volume). An orientation to a problem-to-besolved is displayed here through means other than verbal production: Nancy remedies the problem by putting the glass back in front of Michael.

(8) [Holt:SO88:2:7:1-2] ((Modified standard orthography))

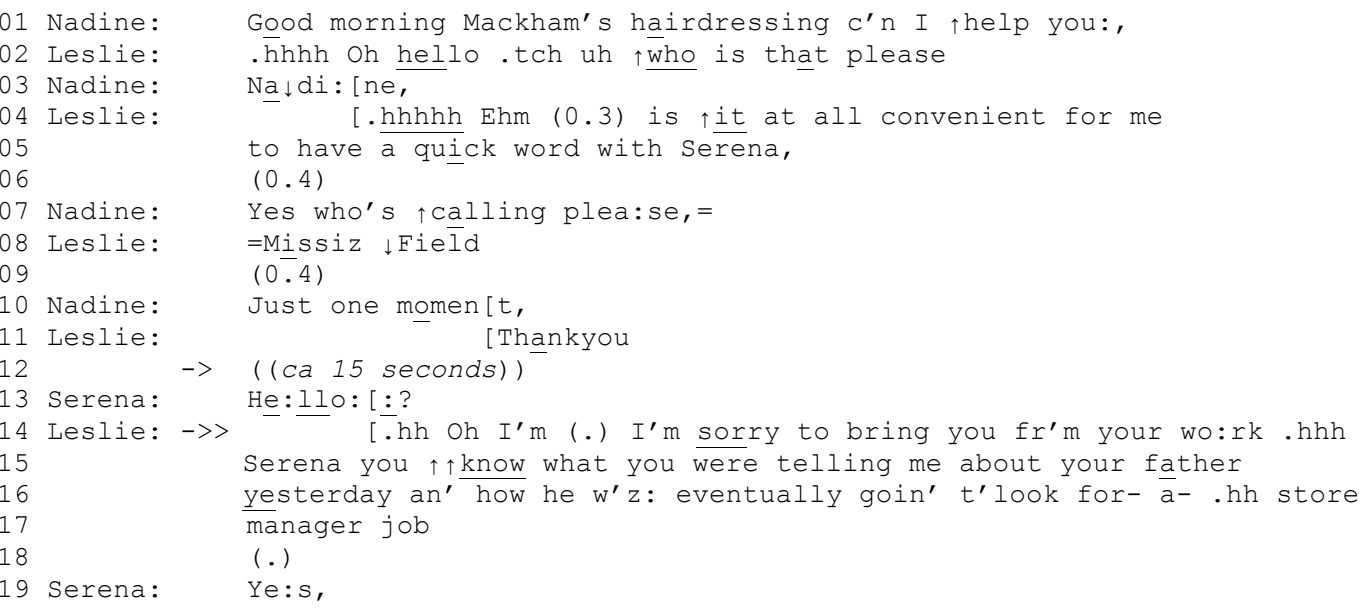

Leslie has called Serena at work. When another person (Nadine) answers the phone (line 1), Leslie orients to the possible inappropriateness of having brought Serena to the phone while she is working 
Pino, Pozzuoli, Riccioni and Castellarin - "Oh” + Apology + Solution

("is $\uparrow \underline{i t}$ at all convenient for me to have a quick word with Serena", lines 4-5). A possible offense/problem may become available through non-verbal features of the interactional environment: the extended silence between the termination of the exchange with Nadine and the moment when Serena becomes available (line 13) can provide Leslie with evidence of the inappropriateness of having called Serena at this time. This contingency can account for the use of the more elaborated ["I'm sorry" + naming of the offense] format (Heritage and Raymond, this volume), by which Leslie articulates an offense on behalf of a party who has not had yet the opportunity to do so (and pre-empts the possibility of such articulation; see, for contrast, extract 5 where Norm complains for having been called at an inappropriate time). The turn initial "Oh" indexes that Leslie has become aware of the possible inappropriateness of the call. In this case, there is evidence that Leslie has not become aware of the possible offense/problem 'just now' (she has already displayed awareness of it at lines 4-5, when talking to the person who answered the phone). Nevertheless, it can be noted that the silence at line 12 can materialise what had previously been a mere possibility (i.e. Leslie may have taken the time elapsed before Serena reached the phone as indicating that Serena was indeed busy at the time of the call). Furthermore, and perhaps more importantly, line 14 constitutes Leslie's first opportunity to display to Serena her orientation to that possible offense/problem as something that Leslie has just realised. Leslie goes on to characterise the circumstance as a possible offense through the apologetic “I'm (.) I'm sorry to bring you fr'm your wo:rk". Unlike the previous examples, Leslie does not follow the apology-component of the turn with a 'solution'. This point requires some elaboration. Leslie finds herself in a situation (having called at a possibly inappropriate time) similar to the caller in extract 5 (another common feature is that, in both cases, the caller can use the extended time elapsed before the call-recipient becomes available on the phone, as a resource to orient to the bad timing of the call). In extract 5, the caller follows his apology with a solution (in the form of an offer to terminate the call), however the environment is different; whereas in extract 5 the ["Oh + Apology + Solution] is deployed after the reason for the call (requesting a lift) has been resolved, in extract 8 the reason for the call (introduced at lines 15-17) has not been presented yet. In this environment, a 'solution' to 
Pino, Pozzuoli, Riccioni and Castellarin - "Oh” + Apology + Solution

the problem is arguably available to Leslie (e.g. letting Serena return to her activities, offering to call at another time, etc.), but for Leslie this would entail abandoning her project (the project for which she called). Furthermore, because it is Leslie who articulates the possible offense/problem on Serena's behalf, there is no direct evidence that Serena finds the timing of Leslie's call inappropriate. These contingencies can account for why Leslie selects not to deliver a "solution" to the problem in her post-apology turn expansion (lines 15-17); instead, she states the reason for the call. In common to the other instances is that the apology-component (with its retrospective orientation to a possible offense) is in turn-medial position and followed by a turn component that displays a more prospective orientation to forwarding the business at hand.

\section{Summary}

Speakers employ the [“Oh” + Apology + Solution] turn construction to deal with a circumstance that has been brought to their attention by the other participant in their prior turn (or that they may have realised by picking up on other features of the immediately preceding interactional environment, as in extracts 7 and 8) and which they ostensibly register through a turn initial "Oh". In five out of six cases, the emerging offense relates to some sort of minor imposition on the recipient: in extracts 3,4 and 6 completion of a sequence (request, arrangement-making, and caller-identification respectively) has been delayed due to a speaker's shortcoming; the call itself is treated as an imposition due to its bad timing in extracts 5 and 8 (the nature of the offense in extract 7 is somewhat different, i.e. appropriation of somebody else's object or good). Speakers retrospectively orient to the complainable character of these impositions by taking responsibility through an apologetic "sorry" or "I'm sorry".

In all six cases speakers recognise that they could (or even should) have independently grasped or used some otherwise available information (Emmersten and Heinemann, 2010) and the failure to do so as having caused the aforementioned impositions. The precise nature of the 
Pino, Pozzuoli, Riccioni and Castellarin - "Oh" + Apology + Solution

information varies across the calls. It regards other's physical location in extract 3 , other's access to a piece information in extract 4, other's engagement in other activities at the time of the call in extracts 5 and 8, other's identity in extract 6 and other's ownership of a physical object in extract 7 . The analysis of extract 8 further suggests that in certain circumstances speakers can select to characterise a possible offense/problem as something that they have just happened to realise, although such realisation has not 'just' happened, strictly speaking. Finally, speakers also move beyond apologising by orienting to the presence of a problem that requires a practical solution, which they provide in a post-apology turn expansion.

\section{How participants collaborate in establishing the sequential primacy of the solution component over the apology component}

The apology and the solution components of the ["Oh" + Apology + Solution] turn construction are not equally treated. In this section we show that, although the apology component is given temporal priority (it is uttered first), the solution component is given sequential primacy. By this we mean that the apology component is not designed to make a response relevant, whereas the solution component is designed to become sequentially consequential and inform subsequent development of the interaction. We rely on the following evidence for this claim: a) the apology is not in turn-final position and often it is not realised with turn-final intonational configuration (Ford and Thompson, 1996); b) recipients do not respond to the apology; c) speakers do not pursue a response to the apology; d) the aftermath of the [“Oh" + Apology + Remedy] turn is shaped by the solution rather than the apology component (either in the form of solution acceptance or, more frequently, by moving on to different matters, hence implicitly treating the problem as solved for all practical purposes).

Table 1: turn constructional and sequential features 
Pino, Pozzuoli, Riccioni and Castellarin - "Oh” + Apology + Solution

\begin{tabular}{c|l|l}
\hline Extract & Turn format & Response to the apology \\
\hline 3 & "Oh" + "I'm sorry" + Solution & No \\
\hline 4 & "Oh" + "sorry" + Solution & No \\
\hline 5 & "Oh" + "I'm sorry" + Laughter + Solution & No \\
\hline 6 & "Oh"+ "sorry" + Laughter + Solution & No \\
\hline 7 & $\begin{array}{l}\text { Non-verbal Solution // } \\
\text { "Oh" + ["sorry" + Naming of the } \\
\text { offense/problem] }\end{array}$ & Yes \\
\hline 8 & $\begin{array}{l}\text { "Oh" + ["I'm sorry" + Naming of the } \\
\text { offense/problem] + Reason for the call }\end{array}$ & No \\
\hline
\end{tabular}

Table 1 illustrates the turn constructional and sequential features that bear on our argument. The apology component is not in turn-final position, with the exception of extract 7 . Here, the solution is produced non-verbally and does not figure in the spoken turn, which ends with the apology component ("sorry" + naming); this feature can partly account for the fact that the apology (or more precisely the 'naming of the offense') receives a response. We now examine the six target turns, reproduced for convenience in the next extracts, where we have highlighted the three turn components: $\mathrm{Oh}+$ Apology + Solution.

(3) $[\mathrm{NB}: I: 3: 1-2]$

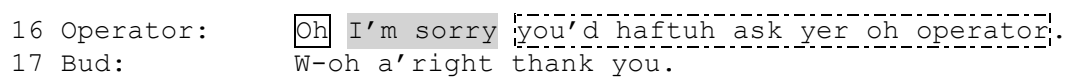

In line 16 of extract 3 , the apology is not the turn-final component and is followed by material whose function is not apologising (Robinson, 2004) but treating the emerging circumstance as a problemto-be-solved. "I'm sorry" is produced with level (i.e. non final) intonation, signalling that it should not be understood as the terminal part of the turn (Ford and Thompson, 1996) and, hence, that a response is not made relevant at this point. The recipient appears to collaborate by only registering and accepting the proffered solution (after the aborted turn beginning "W-"), which also enables a movement towards closure of the call. Although "a'right" can be a response to an apology (Robinson, 2004), here it seems to be used to accept the information provided by the operator (Bud had made the same use of "Alright" in line 8). The operator does not pursue a response to the apology.

(4) [Holt:2:7:1-2] 

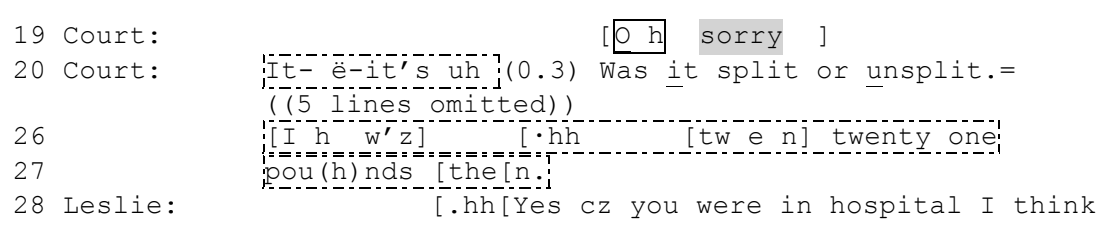

In line 19 of extract 4, "sorry" is not produced as the final turn-component. Although a slight pause ensues before the start of the talk in line 20, perceptually, "sorry" appears to be pronounced with slightly upward intonation, hence projecting turn expansion and not making response relevant at this point. In line 20, Court starts and halts the projected solution ("It- ë-it's uh") and initiates an insert expansion ("Was it split or unsplit."), after completion of which he delivers the solution component (lines 26-27). Leslie collaborates in treating the circumstance as primarily a problem-to-be-solved by not responding to the apology, by receipting the solution (the information about the price) at line 28 ("Yes") and by moving on to other matters. Interestingly, she seems to display an implicit orientation to the apologisable character of the incident by volunteering a reason for why Court may not have remembered the price of the logs: he had been in hospital. This eventually leads to a topic change, which further sanctions the successful completion of the arrangement-making activity which Leslie had launched and which had been delayed by Court's misapprehension. Court does not pursue a response to the apology.

(5) [Holt:SO88:1:2:1-2]

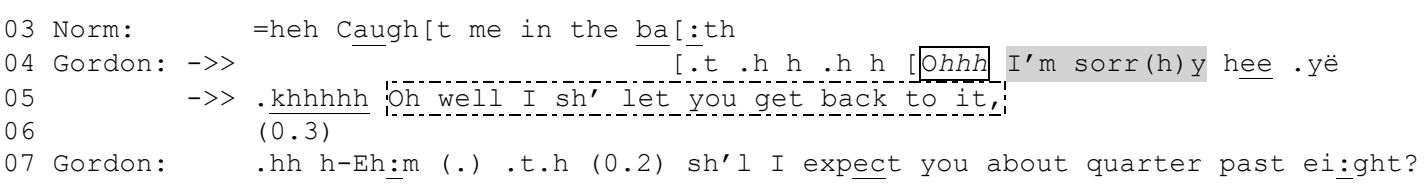

Unlike the previous cases, in extract 5 the post-apology solution component is delayed by laughter, by which Gordon matches Norm's treatment of the circumstance as funny (see the turn-initial laughter particle in line 3). There follows an in-breath which further delays production of the solution component and leaves a space where Norm could respond to the apology. Norm nevertheless refrains from doing so and Gordon expands his turn with a solution component (“'Oh well I sh' let you get 
Pino, Pozzuoli, Riccioni and Castellarin - "Oh" + Apology + Solution

back to it,"). Although the solution does not receive a response it seems to be treated as consequential for the unfolding of the interaction. Gordon appears to take Norm's silence at 1.6 as indicating his tacit assent to the proposed solution, i.e. terminating the call, and he makes a move towards call closure at line 7 by consolidating the arrangements for the evening (Schegloff, 2007).

(6) [Holt:2:2:2:1]

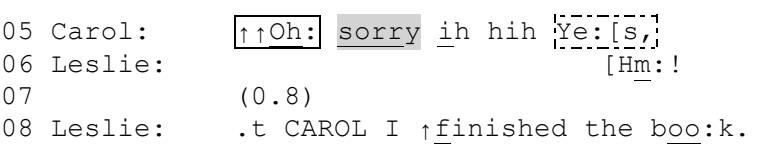

In extract 6, the "sorry" component is not the last component in the turn and is not produced with final intonation (perceptually, it sounds as slightly rising). After two sounds ("ih hih", possibly laughter particles or aborted attempts at pronouncing "Yes"), Carol resolves the caller identification problem by indexing caller recognition ("Ye:s"). Leslie does not respond to the apology, nor does Carol pursue such a response. After a gap at line 8, Leslie moves on to introduce the first topic.

(7) [Deutsch:CDII:88-89]

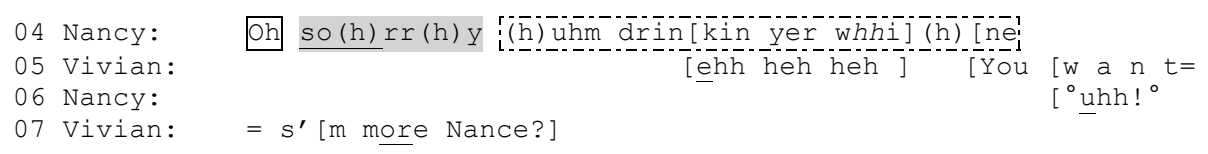

Extract 7 presents some differences from the other cases in the collection. Michael does not articulate the offense/problem (although he alerts Nancy to it with a head movement and by gazing at her); it is Nancy who articulates the offense/problem on Michael's behalf using the ["sorry" + naming of the problem] apology format. Furthermore, Nancy's turn does not contain a solution, which she delivers non-verbally (Nancy puts the glass down in front of Michael). These contingencies can account for the use of the format ["Oh" + "sorry" + naming of the offense/problem]. Since this is also a common format for explicit apologies (Heritage and Raymond, this volume; Robinson, 2004), its use can account for why, unlike other cases in our collection, the problematic behaviour (i.e. the source of the possible offense and the object of the apology) is addressed in next turn: Vivian ironically formulates 
Pino, Pozzuoli, Riccioni and Castellarin - "Oh" + Apology + Solution

Nancy's action as motivated by a search for more wine, hence addressing (albeit non-seriously) its offensive character (Robinson, 2004).

(8) [Holt:SO88:2:7:1-2]

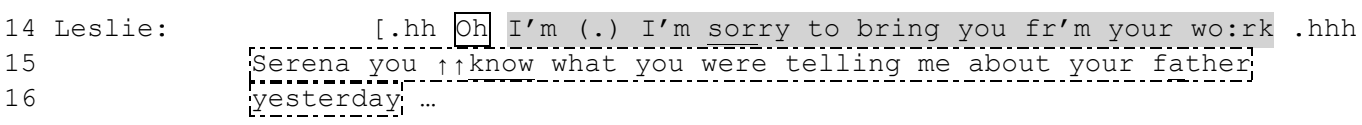

In extract 8, the apology component ("I'm sorry" + naming of the problem) is produced with nonfinal intonation and is followed by an in-breath, projecting turn expansion. Serena avoids taking a turn at this point, thereby displaying an orientation to the apology as a prefatory component to the main function of the turn rather than an action that solicits a response in its own right (Robinson, 2004). There is no pursuit of a response to the apology. We have already observed that this instance is different from other cases in the collection insofar as Leslie selects not to deliver a solution to the problem (particularly in contrast with what happens in extract 5) and instead states the reason for the call. Extract 8 is similar to extract 7 in that the more expanded apology ("I'm sorry" + naming of the problem) formulates a possible offense/problem on the other's behalf (an offense/problem that Leslie may have inferred from the extended silence elapsed before Serena picked up the phone).

\section{Discussion}

The ["Oh" + Apology + Solution] turn construction enables speakers to deal with an emerging circumstance with both a retrospective orientation to a possible offense and a prospective orientation to a problem-to-be-solved. Through a turn-initial "Oh", speakers convey that they had not been previously aware of the offense/problem. By this, they are able to suggest that they had not 'premeditated' the offense and that it was inadvertently occasioned. The minimal format of the apology ("sorry" or "I'm sorry"; Heritage and Raymond, this issue) is proportional to the minor and 
Pino, Pozzuoli, Riccioni and Castellarin - "Oh" + Apology + Solution

transient nature of the offenses (minor impositions endogenous to the ongoing interaction, such as delays in sequence progressivity or the bad timing of a call, associated with the failure to properly use otherwise available information). The more expanded apologies, which include naming the offense (extracts 7 and 8), can be explained by the non-articulation of the possible offense/problem in the preceding talk (Heritage and Raymond, this issue). The turn-medial positioning of the apology component does not make a response relevant, and this is also commensurate to the minor nature of the offense, for which an apology is appropriate but without requiring a dedicated apology sequence (i.e., not without requiring 'absolution'; Robinson, 2004). Recipients collaborate by not responding to the apology and thereby treating it as secondary to the main interactional function of the turn: dealing with the emerging circumstance as a problem and resolving it. One instance (extract 8) shows that the ["Oh" + Apology + Solution] turn construction can be employed in circumstances where the possible offense has not been realised 'just now', strictly speaking. This suggests that, since the [“Oh" + Apology + Solution] turn construction is fitted to circumstances that are primarily treated as problems-to-be-solved and only secondarily as offenses, this practice is also available to speakers for reflexively constituting a possibly imposing behaviour (such as calling at an inappropriate time) as a minor offense, that is, as the unanticipated collateral effect of an otherwise innocent line of action.

\section{Acknowledgments}

We would like to thank Paul Drew, Alexa Hepburn, Renata Galatolo and Piera Margutti for organising the Bologna Conversation Analysis Workshop in March 2013 where we started working on the Apologies Data Set. We are very grateful to Paul Drew and Piera Margutti for their invaluable comments on an earlier draft of this paper. Their input strongly contributed to shape our understanding of the practice described in this study.

\section{References}


Pino, Pozzuoli, Riccioni and Castellarin - "Oh" + Apology + Solution

Emmertsen, S., \& Heinemann, T. (2010). Realization as a Device for Solutioning Problems of Affiliation in Interaction. Research on Language and Social Interaction, 43(2), 109-132

Ford, C., \& Thompson, S. A. (1996). Interactional units in conversation: Syntactic, intonational, and pragmatic resources for the management of turns. In E. Ochs, E. A. Schegloff, \& S. A. Thompson (Eds.), Interaction and grammar (pp. 134-184). Cambridge, England: Cambridge University Press.

Heritage, J. (1984). A change-of-state token and aspects of its sequential placement. In J.M. Atkinson \& J. Heritage (Eds.), Structures of Social Action: Studies in Conversation Analysis (pp. 299-345). Cambridge: Cambridge University Press.

Heritage, J. (1998). Oh-prefaced responses to inquiry. Language in Society, 27(3), 291-334.

Kendick, K. \& Torreria, F. (2014). The Timing and Construction of Preference: A Quantitative Study. Discourse Processes. DOI: 10.1080/0163853X.2014.955997

Kevoe-Feldman, H., \& Robinson, J.D. (2012). Exploring essentially three-turn courses of action: An institutional case study with implications for ordinary talk. Discourse Studies, 14(2), 217241.

Robinson, J.D. (2004). The sequential organization of "explicit" apologies in naturally occurring English. Research on Language and Social Interaction, 37(3), 291-330 .

Robinson, Jeffrey D. (2006). Managing Trouble Responsibility and Relationships During Conversational Repair. Communication Monographs, 73, 137-161.

Schegloff, E.A. (1986). The Routine as Achievement. Human Studies, 9, 111-151.

Schegloff, E.A. (2005). On complainability. Social Problems, 4, 449-476

Schegloff, E.A. (2007). Sequence organization in interaction: a primer in conversation analysis I. Cambridge: Cambridge University Press. 